\title{
Quantitative analysis of post-TAVI aortic regurgitation with cardiovascular magnetic resonance and the relationship to transthoracic echocardiography
}

\author{
Akhlaque Uddin ${ }^{1 *}$, Timothy Fairbairn ${ }^{1}$, Christopher D Steadman ${ }^{2}$, Bernhard A Herzog ${ }^{1}$, Manish Motwani ${ }^{1}$, \\ Ananth Kidambi ${ }^{1}$, Dominik Schlosshann ${ }^{3}$ Daniel Blackman³, Gerry P McCann², Sven Plein ${ }^{1}$, John P Greenwood ${ }^{1}$
}

From 16th Annual SCMR Scientific Sessions

San Francisco, CA, USA. 31 January - 3 February 2013

\section{Background}

Transcatheter Aortic Valve Implantation (TAVI) is increasingly used to treat patients with severe aortic stenosis at high surgical risk. The severity of post-implantation valvular or paravalvular regurgitation has been shown to adversely affect patient outcome. The aim of the study was to assess the prevalence and severity of aortic regurgitation (AR) at 6 months post-TAVI using cardiovascular magnetic resonance (CMR).

\section{Methods}

Twenty five severe aortic stenosis patients underwent a 1.5T CMR (Intera, Philips Healthcare) scan at baseline and 6 months after CoreValve ${ }^{\mathrm{TM}}$ TAVI. LV function was assessed using cine imaging with a steady state free precession pulse sequence. The LV outflow tract was imaged in two planes and through-plane phase contrast velocity imaging was performed perpendicular to the aortic valve and transverse to the aorta at the sinotubular junction. Postprocessing was performed using QMass 7.2 and QFlow 5.2 (Medis, Netherlands). AR severity was defined using regurgitant fraction $(\mathrm{RF})$ as: none to mild $<8 \%$, mild to moderate 8 to $19 \%$, moderate to severe 20 to $29 \%$ and severe $>30 \%[1]$.

Transthoracic echocardiography (iE33, Philips Healthcare) was performed at baseline and 6 months follow-up. Aortic regurgitation was graded using a comprehensive

\footnotetext{
${ }^{1}$ Academic Unit of Cardiovascular Medicine, Multidisciplinary Cardiovascular Research Centre (MCRC) \& Leeds Institute of Genetics, Health and Therapeutics, Leeds, UK

Full list of author information is available at the end of the article
}

integrated approach following the recent Valve Academic Research Consortium (VARC) guidelines.

\section{Results}

Mean age was $80.6 \pm 6.6 \mathrm{yrs}, 44 \%$ were female, Logistic EuroSCORE $19.5 \pm 14.9 \mathrm{LV}$ ejection fraction significantly improved post-TAVI $(52.1 \pm 11.8 \%$ vs. $55.9 \pm 9.6 \%$, $\mathrm{p}<0.0001)$ and reduction in indexed end-systolic LV volume $\left(46 \pm 18 \mathrm{ml} / \mathrm{m}^{2}\right.$ vs. $\left.41 \pm 17 \mathrm{ml} / \mathrm{m}^{2}, \mathrm{p}=0.02\right)$. The end-diastolic volume $\left(95 \pm 18 \mathrm{ml} / \mathrm{m}^{2}\right.$ vs. $91 \pm 20 \mathrm{ml} / \mathrm{m}^{2}$, $\mathrm{p}=\mathrm{ns})$ and stroke volume $\left(48 \pm 10 \mathrm{ml} / \mathrm{m}^{2}\right.$ vs. $50 \pm 10$ $\mathrm{ml} / \mathrm{m}^{2}, \mathrm{p}=\mathrm{ns}$ ) did not change.

There was a significant reduction in aortic RF 6 months post-TAVI (median RF $12.4 \%$, IQR 5.6 to $16.8 \%$ vs. $6.2 \%$ IQR 3.6 to $13.2 \%, \mathrm{p}=0.034$ ) (Figure 1). There was no significant difference between the transthoracic echo grading and CMR grading of aortic regurgitation. (Chi-squared = $3.74 \mathrm{p}=0.159$ ) (Figure 2).

Echocardiography showed there was also a statistically significant reductions in peak forward flow velocity (4.87 $\pm 0.57 \mathrm{~ms}^{-1}$ vs. $\left.1.98 \pm 0.35 \mathrm{~ms}^{-1} \mathrm{p}<0.05\right)$, peak pressure gradient $(96.1 \pm 24.3 \mathrm{mmHg}$ vs. $17 \pm 5.7 \mathrm{mmHg} \mathrm{p}<0.05)$ and mean pressure gradient $(54.8 \pm 15.9 \mathrm{mmHg}$ vs. $8 \pm 3 \mathrm{mmHg}$ $\mathrm{p}<0.05)$ compared to baseline; the effective orifice area (EOA) was significantly larger compared to the baseline state $\left(0.57 \pm 0.03 \mathrm{~cm}^{2}\right.$ vs. $\left.1.63 \pm 0.3 \mathrm{~cm}^{2} \mathrm{p}<0.05\right)$.

\section{Conclusions}

There was an overall reduction in aortic regurgitant fraction post-TAVI even in the presence of pre-existing AR. CMR can be used in the TAVI population, pre- and postprocedure to quantify the degree of aortic regurgitation 


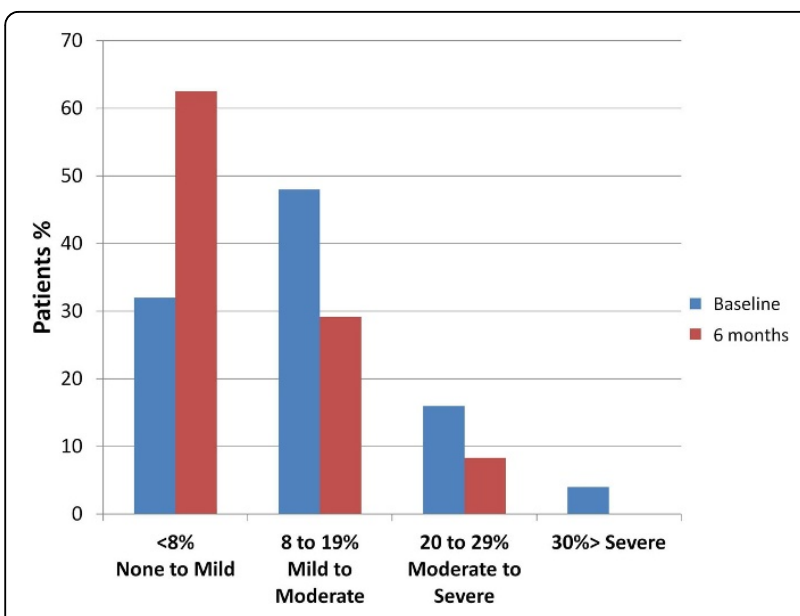

Figure 1 Quantification of aortic regurgitation by CMR phase contrast velocity mapping before and 6 months after TAVI implantation.

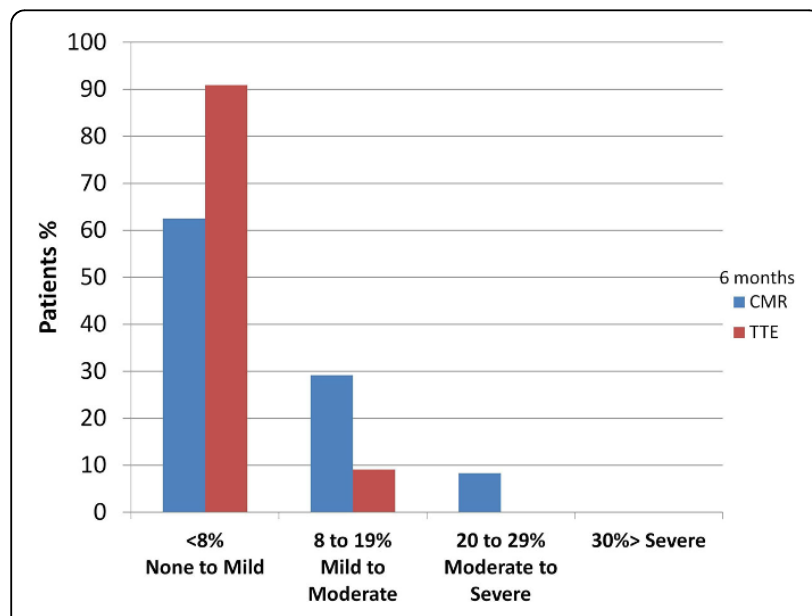

Figure 2 Comparison of aortic regurgitation grading by CMR and transthoracic echocardiography at 6 month follow up.

\section{Funding}

SP is funded by a British Heart Foundation fellowship (FS/10/62/28409).

SP and JPG receive an educational research grant from Philips Healthcare.

\section{Author details}

${ }^{1}$ Academic Unit of Cardiovascular Medicine, Multidisciplinary Cardiovascular Research Centre (MCRC) \& Leeds Institute of Genetics, Health and

Therapeutics, Leeds, UK. ${ }^{2}$ National Institute for Health Research(NIHR) Leicester Cardiovascular Biomedical Research Unit, University of Leicester, Leicester, UK. ${ }^{3}$ Department of Cardiology, Leeds Teaching Hospitals NHS trust, Leeds General Infirmary, Leeds, UK.

Published: 30 January 2013

\section{Reference}

1. Gabriel RS, Renapurkar R, Bolen MA, Verhaert D, Leiber M, Flamm SD, Griffin BP, Desai MY: Comparison of severity of aortic regurgitation by cardiovascular magnetic resonance versus transthoracic echocardiography. Am J Cardiol 2011, 108(7):1014-20.

doi:10.1186/1532-429X-15-S1-P114

Cite this article as: Uddin et al:: Quantitative analysis of post-TAVI aortic regurgitation with cardiovascular magnetic resonance and the relationship to transthoracic echocardiography. Journal of Cardiovascular Magnetic Resonance 2013 15(Suppl 1):P114.

\section{Submit your next manuscript to BioMed Central and take full advantage of:}

- Convenient online submission

- Thorough peer review

- No space constraints or color figure charges

- Immediate publication on acceptance

- Inclusion in PubMed, CAS, Scopus and Google Scholar

- Research which is freely available for redistribution

Submit your manuscript at www.biomedcentral.com/submit 